\title{
XVI. Asrın İlk Yarısında Kratova'da Nüfus ve Demografik Yapı
}

\author{
Selçuk URAL ${ }^{1}$ \\ $\ddot{O} z$
}

Osmanlı Devleti hükmettiği coğrafyalarda kendine özgü bir idare tarzı benimsemiştir. Bu tarz Balkanlarda gerçekleştirdikleri fetihler akabinde bölgede uzun süreli ve kalıcı etki bırakmalarını sağlamıştır. Fethettikleri bölgelerde geleneksel tahrir işlemi sayesinde düzenli olarak nüfus ve arazi sayımlarını gerçekleştirmişlerdir. Devletin tüm kademelerinde hissedilen bu anlayış sayesinde de Osmanlılar hem hazinelerine gelir sağlamışlar hem de gerçekleştirecekleri akınlarda gerekli asker gücünü edinebilmişlerdir. Böylece egemen oldukları coğrafya ile toplumları daha iyi kavrayıp yönetebilmişlerdir. Vergiye tabi nüfusun belirlenmesiyle de hem iktisadi hem de idari düzenin kurulmasını sağlamıştır. Bu çalışmada da XVI. asrın ilk yarısına ait arşiv kayıtları eşliğinde Kratova'nın ve bölgenin nüfus ve demografik yapısı ortaya çıkarılmak amaçlanmıştır. Böylece Osmanlı Devleti’nin bahsi gen yüzyılda Kratova özelinde Balkanlarda uygulamaya çalıştığı nüfus ve iskân politikası aydınlatılmaya çalışılmıştır.

Anahtar Kelimeler: Kratova, Tahrir, Nüfus, Demograf

\section{Population and Demographic Structure in Kratova in the Firsth Half of the XVI Century}

\begin{abstract}
The Ottoman Empire adopted a unique style of administration in the geographies it ruled. The conquests they carried out in the Balkans in this manner enabled them to leave a long-lasting and permanent effect in the region. They carried out regular population and land censuses in the regions they conquered with the traditional tahrir process. Thanks to this understanding felt at all levels of the state, the Ottomans both provided income for their treasury and obtained the necessary military power in their expeditions. Thus, they were able to better understand and manage the geography and societies they dominated. At this point, it is important to determine the population that will be subject to tax. By determining the population to be taxed, they ensured the establishment of both an economic and administrative order. XVI in this study. It is aimed to reveal the population and demographic structure of Kratova and the region with the archive records of the first half of the century. Thus, the population and settlement policy that the Ottoman Empire tried to implement in the Balkans, especially in Kratova, was tried to be enlightened.
\end{abstract}

Key Words: Self, Self Esteem, Stress, Coping with Stress, Stress Management

Atıf İçin / Please Cite As:

Ural, S. (2021). XVI. Asrın İlk Yarısında Kratova'da Nüfus ve Demografik Yapı. Manas Sosyal Araștırmalar Dergisi, 10(3), 1951-1963.

Geliş Tarihi / Received Date: 05.04.2021

Kabul Tarihi / Accepted Date: 21.04.2021

\footnotetext{
${ }^{1}$ Dr. Öğr. Üyesi - Türkiye Sakarya Uygulamalı Bilimler Üniversitesi, sural@subu.edu.tr

(D) ORCID: 0000-0002-5734-8302
} 


\section{Giriş}

Dünya genelindeki pek çok coğrafi bölge, üzerinde varlıklarını belirli sürelerde devam ettirebilen insan topluluklarıyla anılır olmuştur. Ancak bahse konu bölgeler istikrarsız yapıları sebebiyle çoğu kez ise kısa süreli egemenliklerin izlerini kolayca silebilmiştir. Bu doğrultuda tarih boyunca Balkan coğrafyası gerek Slavların gerekse Osmanlılar öncesindeki Türklerin yaşayıp kendilerine vatan haline dönüştürdükleri bir alana karşılık gelmiştir. Lakin Balkanların bir Türk yurdu haline dönüşmesi, Osmanlıların XIV. asrın ikinci yarsısından itibaren giriştikleri ve temelinde siyasi hakimiyet alanlarını arttırmak, yeni topraklar keşfedip ele geçirmek ve inançlarını yaşatıp etki alanını genişletmek gibi maksatlar olan akınları sayesinde gerçekleşebilmiştir. Osmanlıların Balkanlara girişiyle birlikte yaklaşık beş asır devam ettirmeyi başarabildikleri bu istikrarlı siyasi süreçle birlikte Rumeli diyarları doğal olarak Türk-İslam tipi bir yerleşim alanına dönüşmüştür. Bu dönüşüm ise kendisini daha çok bölgenin demografik yapısıyla birlikte nüfus verileri üzerinde hissettirmiştir. Hal böyle olunca bölgenin demografisi ile nüfus bilgilerini içeren Osmanlı tahrirleri ihtiyacımız olan gelişim verilerini bizlere sunmuştur.

XIV. asın ikinci yarısı itibariyle gerçekleşen Osmanlı akınları sayesinde fethedilebilen ve günümüzde Kuzey Makedonya'da yer alan Kratova şehri de bahsettiğimiz bu dönüşümü yaşayan yerleşimler arasında yerini almıştır. Şehrin maden zenginliği ve diğer stratejik merkezlere göre farklı bir noktada sahip olduğu değer buraya olan ilgiyi de arttırmıstır. Bu çalışmada Kratova özelinde Osmanlı hâkimiyetiyle beraber gelişen demografi yapısal durum ve nüfus istatistikleri üzerinde durarak Osmanlı egemenliğindeki bir yerleşim alanının XVI. asın ilk yarısındaki mevcut durumu ve o tarih itibariyle geçirdiği dönüşümü ortaya koymaya çalışacağız.

\section{Yöntem}

Çalışmada, Türkiye Cumhuriyeti Cumhurbaşkanlığının Başkanlık Osmanlı Arşivinde (BOA) yer alan ve Balkanlardaki şehirlerin demografi ve nüfus sayılarıyla ilgili verileri içeren XVI. yüzyılda ait arşiv dokümanları incelenmiştir.

Başkanlık Osmanlı Arşivi Tapu Tahrir tasnifindeki defterler ile Maliyeden Müdevver tasnifindeki defterlerin demografik yapı ve nüfus verileri bilgilerinden hareketle, Osmanlı Devleti'nin Rumeli Balkan coğrafyasında uygulamaya çalıştığı fetih ve iskân politikası aydınlatılmaya çalışılmıştır. Arşiv kayıtlarının değerlendirilmesi sonucu elde edilen sonuçlar da Osmanlı ana kaynakları ve ikinci el kaynaklardaki dönemsel araştırmalara ait bilgilerle desteklenmiştir.

\section{Kratova'nın Konumu ve Adı}

Kratova şehri günümüz Kuzey Makedonya Devleti sınırları içinde ve ülkenin kuzeydoğu bölümünde Kumanova, Eğridere (Kriva Palanka), Kiliseli ve Koçani yerleşimlerinin oluşturduğu dörtgenin tam ortasında yer almaktadır. Osmanlıların Balkanlardaki hakimiyetleri esnasında Kırat Ova şeklindeki adıyla anılan şehir, Makedonca Kpatobo, Arnavutçada ise Krotovo olarak isimlendirilmektedir. Bu ismin bölgenin maden kaynağı durumundaki dağlık, sarp ve kayalık arazilerin yapısından hareketle Krater, Kratis ve Koritos şeklindeki ifadelerden türetilerek ortaya çıktığ tahmin edilmektedir.

Kratova şehri, Balkanlarda son dönemde etkinliğini yitirmiş haldeki yanardağlardan birisi olan Osogova Yanardağının eteğinde kurulmuştur. Bu dezavantajına rağmen Vardar Nehrinden beslenip şehrin tam ortasından geçerek çevre arazileri besleyen Zletovo ile Kriva Nehirleri sayesinde Kratova ve civarı hem tarımsal faaliyetler hem de madencilik bakımından öne çıkabilmiştir. Günümüzde de Kuzey Makedonya Devletinin siyasi yapılanması içerisinde bir belediye idari birimi şeklinde yönetilmektedir. Merkeziyle beraber 31 birimde yerleşim gösteren şehrin 2002 yılı nüfus sayımı verilerine göre 10.441 kişilik nüfusu bulunmaktadır. Balkan coğrafyasına soğuk ve sert iklimine rağmen yağış alması özelliğinden ötürü hem kış hem de yaz mevsiminde 1 lıman bir iklim ortamı göstermektedir. Yer altı zenginlikleri olarak bakır, gümüss, kurşun, altın ve çinko bakımından zenginliğiyle bilinmektedir. Bu durumun yanı sıra ikliminin elverişliliği sebebiyle tarım arazilerinde birçok tahıl ürünü yetiştirilebilmektedir (Kahraman ve Dağlı, 2010, s. 779; Republic of Macedonia Municipality Kratovo, 2015, https://finance.gov.mk/wpcontent/uploads/2009/09/PAD_Kratovo-za-na-web.pdf; Kratova Belediyesi, 2021, http://www.opstinakratovo.gov.mk/).

\section{Kratova'nın Osmanlılar Tarafından Fethi}

Yüzölçümü bakımından sınırlı bir alanı ifade etmesine karşın Kratova zengin yer altı kaynakları ve geçiş güzergahı üzerinde yer alması sayesinde tarih boyunca Balkanlardaki kadim yerleşim alanları arasında 
yer almıştır. Kratova yerleşim bölgesinin tarihi geçmişi milattan önce VI. asra kadar dayandırılmaktadır. Milattan sonra V. yüzyıla değin Roma İmparatorluğunun hakimiyetinde kalan şehir, X. yüzyıla kadar ise Bizans'n siyasi egemenliğinde yönetilmiştir. Kısa bir süre (980-1015) Sırp Krallığınca idare edilen Kratova, XIII. yüzyllda yeniden Bizans'ın kontrolüne girmiştir. Kratova'daki Osmanlı hakimiyeti ise XIV. asrın ikinci yarısı itibariyle başlamışır. Şehrin geçirdiği bu tarihi süreç dikkate alındığında, Kratova'nın gerek Slavların gerekse Türklerin Balkanlardaki siyasi egemenliklerinde mühim bir yerleşim alanı olduğu anlaşılmaktadır. Bu önem şehrin üzerinde yer aldığı stratejik coğrafi konumu, tarımsal faaliyetlerin yapılabilirliği ve maden yataklarından kaynaklı iktisadi avantajdan kaynaklanmıştır. Bu haliyle Kratova'nın Türkler açısından kıymetiyse; Osmanlıların Avrupa'nın içlerine doğru ilerleme hedefli akınlarında sol kol olarak isimlendirdikleri güzergâh üzerinde yer alıp, Köstendil üzerinden Tuna mıntıkası hakimiyetlerinde bir geçiş yolu üzerinde yer almasından kaynaklanmıştır (Telli, 2020, s. 308;).

Osmanlı kaynakları Kratova'nın fethinin tam tarihini bildirmiş olmasalar da şehrin yakın çevresinin Sultan I. Murad'ın Rumeli fütuhatı döneminde başlatılan akınlar neticesinde ilk kez ele geçirildiği tahmin edilmektedir. Makedonya'nın Manastır, Ohri, İştip ve Pirlepe gibi şehirlerinin de bu dönemde gerçekleşen akınlarla fethedildiği bilindiğinden dolayıdır ki Kratova'nın da XIV. asrın son çeyreği bölümünde ele geçirildiği fikri ön plana çıkmıştır. Balkan coğrafyası üzerinden Adriyatik’e kadar ulaşabilmeyi başaran bu Türk birliklerinin başında da Hayreddin Paşa ve Gazi Evrenos Bey yer almıştır. Lakin Osmanlıların Kratova'daki kesin hakimiyetleri Sultan Bayezid'in Kosova ve Bulgar sahasına doğru giriştiği akınlar sürecinde sağlanabilmiştir. Evrenos Bey ile Paşa Yiğit Bey önderliğinde gelişen Osmanlı ilerleyişi neticesinde, 1391 tarihinde Üsküp şehri ile geniş maden yataklarına sahip Kratova'nın da fethi gerçekleştirilmiştir. Böylece Kratova’nın da içinde yer aldığı kuzeydoğu Makedonya siyasi coğrafyası hem Bulgaristan hem de Arnavutluk üzerine gerçekleştirilmesi planlanan akınlarda bir üs noktasi haline gelmiştir (Ercan, 1989, s. 77; Baştav, 1989, s. 79; Emecen, 2014, s. 343; İnalc1k, 1992, s. 232).

\section{Kratova'da Demografi, Yerleşim ve Tarımsal Faaliyetler}

Kratova, XVI. asırda Osmanlı idari yapısı içerisinde Köstendil Livasına kayıtlı bir kaza merkezi statüsü olarak yer almıştır. Bu döneme ait hazırlanmış 1519, 1530 ve 1550 tarihli tahrir defterleri verilerinde ve maliyeden müdevver defterlerindeki bilgilerde padişah hassı toprakları arasında kayıt altına alınmıştır. 1519'a ait kayıtlarda Köstendil Vilayetini oluşturan ve nefsleriyle birlikte ayrıca kaydedilmiş nahiyeler Menlik, İştip, Ustrumca, Ilıca, Bedriç, Ivranya, Radomir, Dupniçe, Tikveş, Praşova, Şirişnik arasinda Kratova'da kendi kaza merkeziyle birlikte yer alırken, vilayetin tamamında ayrı bir nefsi olmadan kaydedilmiş Petriç, Koçana, Koniçe, Pürtlü, Piyaniçe, Morihova, Boyimiye, Moroviçe, Nogoriçe, Doyran, İnegoş, Polaniye, İpşine, Gorna Krayişte nahiyeleri Köstendil'i oluşturmuştur (BOA MAD nr.170, s. 3555; BOA TT nr.167, s. 3-613; BOA, 2003, s. 11-46).

1519 tarihli ve 74 numaralı Tahrir Defteri ile aynı tarihte hazırlanmış 170 numaralı Maliyeden Müdevver defterinde Kratova'nın nüfusu iki farklı tarzda kaydedilmiştir. Defterlerde nefs ifadesiyle nahiye merkezindeki nüfus kastedilirken, Kaza-i Kratova ifadesiyle de bu nefs dışında kalan bölge yani kırsaldaki köyler işaret edilip bu haliyle kayıt altına alınmıştır. Böylelikle Kratova'nın XVI. asırdaki demografik verileri arşiv kayıtlarında bu tarzla bir işleyişle yer aldığından dolayı, bu çalışmada da nefs ve bu nefs etrafinda teşekkül etmiş köylerdeki nüfus ayrı ayrı ele alınmıştır.

Arşiv kayıtlarındaki verilerde 1519'da Kratova'daki demografik yapının Gayrimüslimler, Müslimler ve Yahudiler etrafında şekillendiği görülmüştür. Bahsi geçen tarihe ait kayıtlarda Kratova'da ikamet eden bu üç farklı inanç grubundan Gayrimüslimler için Gebran ile Gebr, Müslümanlar için Müslim, Yahudiler için de Yahudiyan ifadeleriyle bahsedilmiş ve nüfus verileri de bu şekilde kaydedilmiştir.

Böylelikle aynı tarihte padişah hassı olarak zikredilen Nahiye-i Kratova'da yerleşim; bir nefs ile bu merkezin etrafinda mevcut 21 karyeden müteşekkildir. Ayrıca nahiyenin merkezindeki yapılaşma mahalleler etrafinda şekillenmiştir. Bu mahalleler de Cemaat-i Müslim, Cemaat-i Gebran ve Cemaat-i Yahudiyan şeklindeki ifadelerle kayıt altına alınmıştır.

Nihayetinde 1519 tarihinde Kratova'nın merkezindeki demografik yapı kendisini 15'i Gebran, 1’i Yahudiyan ve 1'i de Müslim olmak üzere toplam 17 mahallede; 982 Gebran, 155 Müslim, 10 Yahudi hane ve 65 Bive olmak üzere bir nüfus dağılım şeklinde göstermiştir (BOA TD nr.74, s. 1-5; BOA MAD nr.170, s. 3-9). Tüm bu veriler neticesinde de 1519 'da Nefs-i Kratova'daki toplam nüfusun yaklaş1k 5800 kişiden müteşekkil olduğu tahmin edebilmekteyiz. Aynı tarihte Nahiye-i Kratova'nın nefs'i dışında kalan 21 karyesindeki demografik dağıllım ise 18 Müslim, 1189 Gebran hane ile 26 Mücerred ve 34 Bive (BOA, TTd 
URAL

XVI. Asrın Ilk Yarısında Kratova'da Nüfus Ve Demografik Yapı

nr.74, s. 2-3; BOA MAD nr.170, s. 10-16) şeklinde ortaya çıkarken, bu veriler sonucunda Kratova kırsalındaki tahmini nüfusun da yaklaşık 6095 kişiden ibaret olduğunu söyleyebiliriz. Bu tarihte Kratova kırsalında Yahudi nüfusla karşılaşılmamıştır. Kaldı ki XV ve XVI. yüzyıllarda Osmanlı ahalisi içerisinde kaydedilmiş Yahudi toplumunun Kratova'nın da içinde yer aldığı Balkanlar bölgesindeki civar şehirlerden olan Selanik ile Üsküp'te de genellikle yerleşim merkezlerinde iskân edildikleri bilinmektedir (Kiel, 2009, s. 353; İnbaş1, 2012, s. 378).

Kratova kazası genelindeki nüfusun sayısal karşılığı hakkında yaptığımız tahmini yaklaşımları da arşiv kayıtlarındaki hane, mücerred ve bive sayılarından hareketle ileri sürdügümüzü belirtmek isteriz. Bu vesileyle çalışmamızda, tahrir defterlerindeki yerleşim bölgelerinin nüfusunun hesaplanmasında genellikle kabul görüp kullanılan ve her haneyi kasabalarda 5, daha büyük şehirlerde de 10 kat sayısıla çarparak sonuca ulaşan yaklaşımı kabul ederek tahmini nüfus sayılarına ulaşmaya çalışılmıştır. Daha sonraysa mücerred, bive muaf sayıları da genel nüfus sayısına ekleyerek nihai nüfus rakamlarına ulaşılmaya çalışılmıştır (Göyünç, 1979, s. 332; Çiçek, 1995, s. 97; Barkan, 1953, s. 12).

Bu doğrultuda ve sonuç olarak 1519 tarihinde Kratova'nın hem kaza merkezindeki mahalleleri özelinde hem de kırsalındaki köy yerleşim alanlarında kayıtlı toplam nüfusun yaklaşık 11.895 kişiden müteşekkil olduğunu tahmin edebiliriz. Aynı tarih itibariyle kaza merkezi ile bu merkez dışında kaydedilmiş karyelerin nüfusu ve demografik dağılımları aşağıdaki tablo ve grafikler eşliğinde gösterilmeye çalışılmıştır. Ayrıca kaza merkezindeki demografik yapıyı göstermesi açısından merkez yerleşimindeki mahalle isimlerini içeren bilgiler de bir diğer tablo ile ifade edilmiştir.

Tablo 1. 1519'da Nabiye-i Kratova'da Nüfus

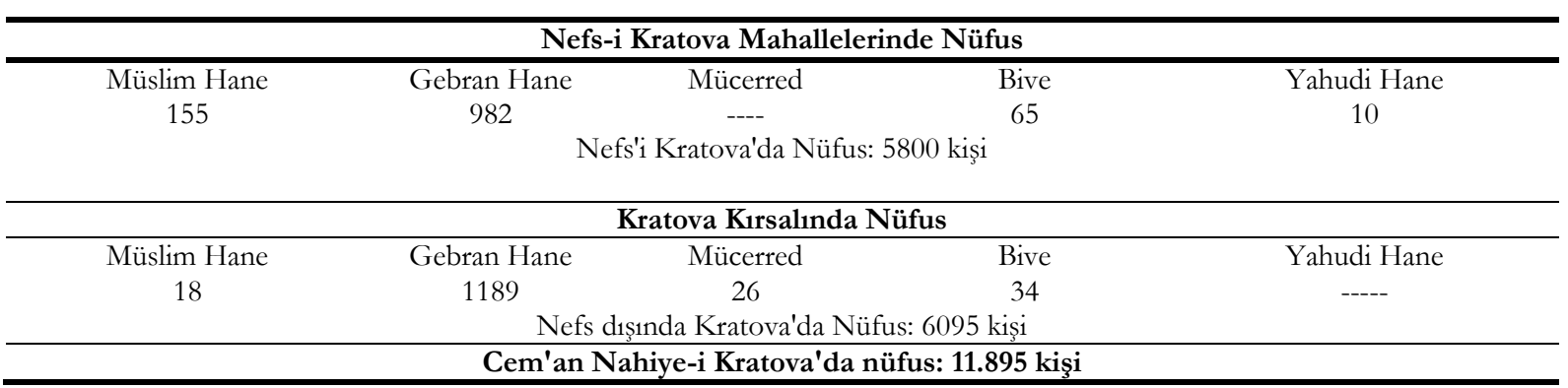

Kaynak: BOA, TT.nr.74, s. 1-5; BOA MAD nr.170, s. 3-9.

Tablo 2. 1519'da Nefs-i Kratova'da Maballeler

\begin{tabular}{lll}
\hline & \multicolumn{1}{c}{ Mahalle-i Gebran } \\
\hline 1. Pop Senat & 6. Kamtanak nam-1 diğer Pop Nikola & 11. Pop İştanişe \\
2. Pop İstango & 7. Pop Nikola & 12. Pop Gorko \\
3. Pop Yovan & 8. İzlatar nam-1 diğer Pop Nikola & 13. Pop Dimitri \\
4. Pop Todor & 9. Pop Petko nam-1 diğer Pop İstepan & 14. İzlokuke \\
5. Mavralu Pop & 10. Pop İstepan & 15. Pavel \\
Mahalle-i Müslim & \multicolumn{1}{c}{ Mahalle-i Yahudiyan } & \\
1.Kratova & 1.Cemaat-i Yahudiyan &
\end{tabular}

Kaynak: BOA MAD nr.170, s. 3-9.
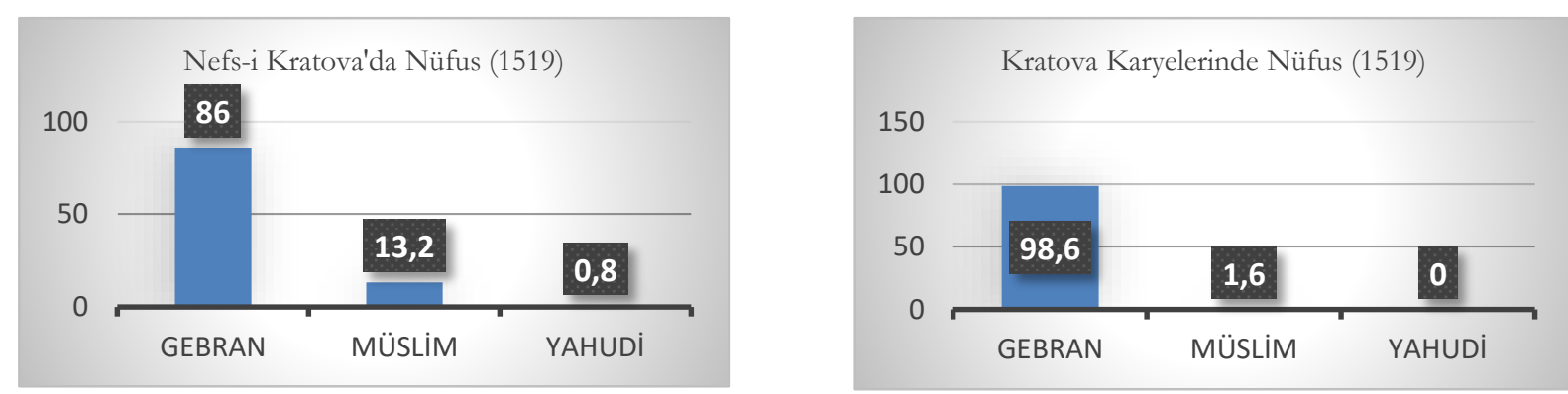

Grafik 1. 1519'da Kratova Genelinde Demografik Dağllım

Kaynak: BOA, TT.nr.74, s. 1-5; BOA MAD nr.170, s. 3-9. 
Osmanlı idari sistemindeki yerleşim birimleri arasındaki köyler vergiye mükellef nüfuslarına bağlı olmaksızın devlet kayıtlarında karye şeklinde isimlendirilmiştir. Bu idari taksimat içerisinde köyler genellikle gelirleri kapsamında en alt birimi karşılamasına rağmen sistemin en mühim yapı taşları durumundadır. Bu haliyle kayıt altına alınan köy yerleşim birimleri gerek tarımsal faaliyetlerin gerekse hayvancılık uğraşının yürütüldüğü ve aynı zamanda ordunun nefer ihtiyacını karşılayan sipahilerin de yer aldığı birimlerdir (Gümüşçü, 2001, s. 98-99). Bu durumun Kratova kazasında da benzer bir nitelik taşıdığını ifade edebilmekle birlikte buradaki madencilik faaliyetlerinin yoğunluğu hasebiyle kazanın merkezinde kayıtlı nüfusu daha ziyadesiyle karşıladığı söylenebilir. Böylelikle Kratova kırsalında yer alan karyelerde Rumeli coğrafyasının genelinde olduğu gibi tarımsal faaliyetler sürdürülmeye çalışılmıştır.

Balkan coğrafyasındaki genel bir nitelik olan dağlık, taşlık ve parçalı arazi şartları, tarımsal yaşam ve üretim konusunda diğer bölge şehirleri gibi Kratova için de en belirgin şart durumundadır. Bu haliyle Kratova kazasında ziyadesiyle madencilik faaliyetleri ön plana çıkmış ve mühim bir gelir kapısı olarak nüfusun birincil tercihi olmuştur. Tüm bu olumsuz şartlara rağmen bölgenin fiziki durumunun elverdiği ölçüde gerçekleştirilmeye çalışılan tarımsal faaliyetler ise daha ziyade meyve ve sebze yetiştiriciliği ile hububat üretimi etrafinda şekillenmiştir.

Böylelikle Kratova'nın merkezi dışında kayıtlı köylerdeki tarımsal faaliyetlere dikkat edildiğinde çeşitli meyve-sebzenin yetiştirilirken bu ürünlerden elde edilen farklı ürünlerin de ortaya çıkarıldığı anlaşılmaktadır. Örneğin bölgede yetiştirilen üzümden elde edilen şıranın bölgedeki ünü bilinmekle birlikte alınan vergi miktarlarından da Kratova kırsalında şıracılık faaliyetinin oldukça yaygın olduğu anlaşılmaktadır. Ayııca yine hınta, alef, burçak, giyah gibi otlanın yetiştirilmesi ile mahbub'a dayalı vergi geliri kayıtlarından anlaşıldığı üzere bu ürünler sayesinde bölgede büyük ve küçükbaş hayvancılık faaliyetlerinin de sürdürülebildiği anlaşılmaktadır. Hayvancilık adına bazı köylerde hınzır şeklindeki ifadesiyle domuz bakımı ve üretiminin de varlığı söz konusudur. Ayrıca Kratova merkezi dışında kayıtlı köylerin hemen hemen tamamında yer alan ve vergi kayıtlarındaki yoğunluğuyla dikkati çeken alef vergisinden de anlaşılacağı üzere Kratova kırsalında arıcılık faaliyetleriyle birlikte bal üretiminin de yaygın olduğundan bahsedilebilir (BOA MAD nr.170, s. 10-16; BOA TT nr.267, s. 472-490). Nihai olarak 1519 'da Kratova kırsalında tarımsal faaliyetlerinden bahsedebildiğimiz karyelerin isimleri de aşağıdaki tablo eşliğinde gösterilmeye çalışılmıştır.

Tablo 3. 1519'da Kaza-i Kratova'da Karyeler

\begin{tabular}{lll}
\hline & \multicolumn{1}{c}{ Karye İsimleri } \\
\hline 1. Petrova Kukiç & 8. Koyraniçe & 15. İşagotin \\
2. Zelezniç & 9. Sakurliçe & 16. Virbiçe \\
3. Tularava & 10. İşlakova & 17. Nezlayova \\
4. Talaşmaniç & 11. Kilinofça & 18. Kinyejlova \\
5. Jeçvalova & 12. Gorna Kratova & 19. Koyko Kula \\
6. Prikofça & 13. Lesnova & 20. İştavkoliç \\
7. Novasil & 14. Muşkova & 21. Dumov Lukov \\
\hline
\end{tabular}

Kaynak: BOA TT nr.267, s. 472-490; BOA TT nr.74, s. 1-5; BOA MAD nr.170, s. 10-17.

Tarihler 1530'u gösterdiğinde padişah hassı olma özelliğini kaybetmediği anlaşılan Kratova'da 167 numaralı Muhasebe-i Vilayet-i Rum İli defteri kayıtlarına göre yine bir nefs ve bu merkezde kayıtlı 28 mahallenin yer aldığı anlaşılmıştır. Bu mahallelerin 24'ünde Gayrimüslimler kayıtlı iken 1'inde cemaat-i Yahudiyan ifadesiyle Yahudiler, 3'ünde de Müslümanlar yer almışlardır (BOA, 2003, s. 2-38). Lakin çalışmada Kratova'nın kaza merkezi nüfusu hakkında bir bilgiye yer verilmeyip kaza genelindeki hane bilgileri paylaşılmışır. Buradan hareketle biz de hem Kratova merkezi ile kırsalındaki karyeler özelindeki demografik yapıyla birlikte nüfus tahminlerimizi ayrı ayrı olmak üzere belirtmek tercihinde bulunduk.

Böylelikle bahsi geçen tarihte Kratova merkezindeki 28 mahallede nüfus 606 Gebran hane, 11 Yahudi hane, 165 Müslim hane ve 73 Bive olmak üzere toplam 782 hane şeklinde kayıt altına alınmıştır (BOA TT nr.167, s. 245). Nihayetinde 1530 'da nahiye merkezindeki nüfusun yaklaşık 3983 kişiden müteşekkil olduğunu söyleyebiliriz. Ayrıca 11 yıl öncesinde yapılmıs bir önceki tahrir sayımına göre Kratova kaza merkezindeki mahalle sayısının artmış olmasına rağmen genel nüfusun hane bazında ve gayrimüslim ahali nazarında belirli bir düzeyde de olsa düşüş yaşadığı anlaşılmıştır. Müslüman ve Yahudi ahalinin nüfusundaysa hem mahalle sayıları bazında hem de genel nüfus sayısı olarak düşük ivmede de olsa bir artışın yaşandığ anlaşılmıştır. Bu durum daha önce de bahsettiğimiz doğrultuda Müslim ve Yahudilerin 
URAL

XVI. Asrın İk Yarısında Kratova'da Nüfus Ve Demografik Yapı

Balkanlarda genel olarak kaza merkezlerine iskân edilmeleriyle doğru orantılı olarak açıklanabilir (Beldicianu, 1995, s. 166-167).

1530 y1lı itibariyle Kratova'nın kırsalındaysa 5 vakıf ve 3 emlakin karye ile birlikte toplam 54 karyenin varlığı defter verilerinden anlaşılmıştır. Yine bu karyelerde 2101 Gebran hane, 204 Gebran Mücerred, 162 Bive, 174 Müslim hane kayıt altına alınmıştır (BOA TT nr.167, s. 245-248; BOA, 2003, s. 38). Tüm bu veriler 1şı̆̆ında ve 1530 'da Kratova kırsalındaki karyelerin nüfusunun da yaklaş1k 11.741 kişiden ibaret olduğu tahmin edilebilir. Nihai olarak bahsi geçen tarihte Kratova'daki toplam tahmini nüfus ise yaklaşık olarak 15.724 kişiden müteşekkildir. 1530'da kaza merkezi ile bu merkez dişında kaydedilmiş karyelerin demografik dağılımı ile nüfus istatistikleri aşağıdaki tablo ve grafikler eşliğinde gösterilmeye çalışılmıştır. Bir diğer tablo ile kaza merkezindeki mahalle isimleri de ayrıca ifade edilmiştir.

Tablo 4. 1530'da Nabiye-i Kratova'da Nüfus

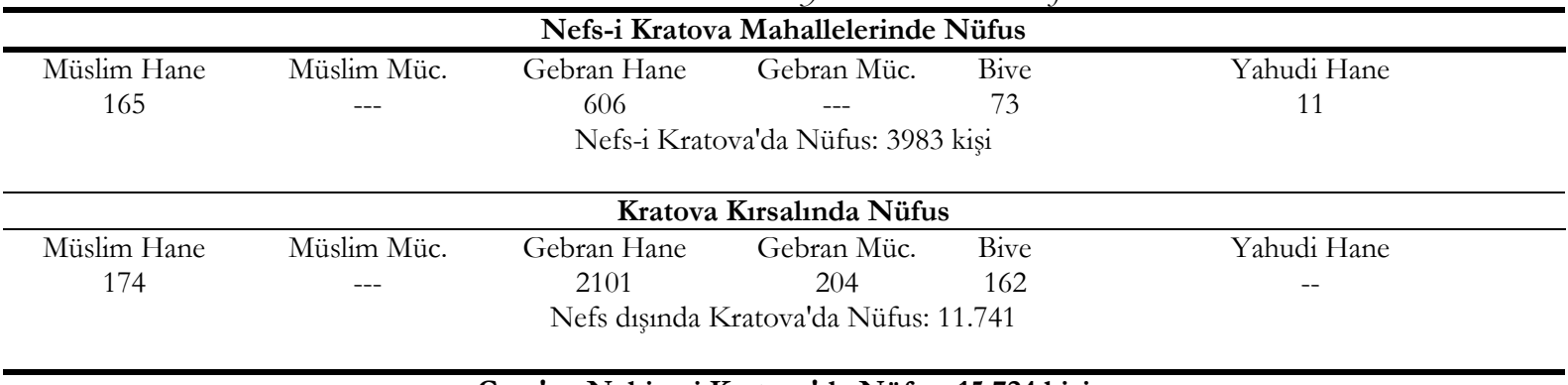

Kaynak: BOA TT nr.167, s. 245-248; BOA, 2003, s. 2-38.

Tablo 5. 1530'da Nefs-i Kratova'da Maballeler

\begin{tabular}{lll}
\hline & \multicolumn{1}{c}{ Mahalle-i Gebran } \\
\hline 1. Pop İnbomenik & 9. Mala & 17. Pop Petko \\
2. Pop Todor & 10. Pop İstanşe & 18. Pop İstoyko \\
3. Pop Dimitri & 11. Pop Yovan-1 diğer & 19. Yondar \\
4. Pop Radliç & 12. Kalugun & 20. Zerkerilin \\
5. Pop Pavli & 13. Dobra Koge & 21. Pop Denak \\
6. Pop Mihal & 14. Broto Pop & 22. Pop Gorko \\
7. Pop Reka & 15. Pop İștefan & 23. Pop Nikola \\
8. Pop Yovan & 16. Doykin & 24. Dugoçovik \\
\hline & \multicolumn{1}{c}{ Mahalle-i Müslim } \\
\hline 1. Cami & 2. Hacı Kemal & 3.Darbhane \\
\hline \multicolumn{2}{c}{ Cemaat-i Yahudiyan } & \\
\hline Kaynak: BOA, 2003, s. 38; BOA TT nr.167, s. 245 &
\end{tabular}
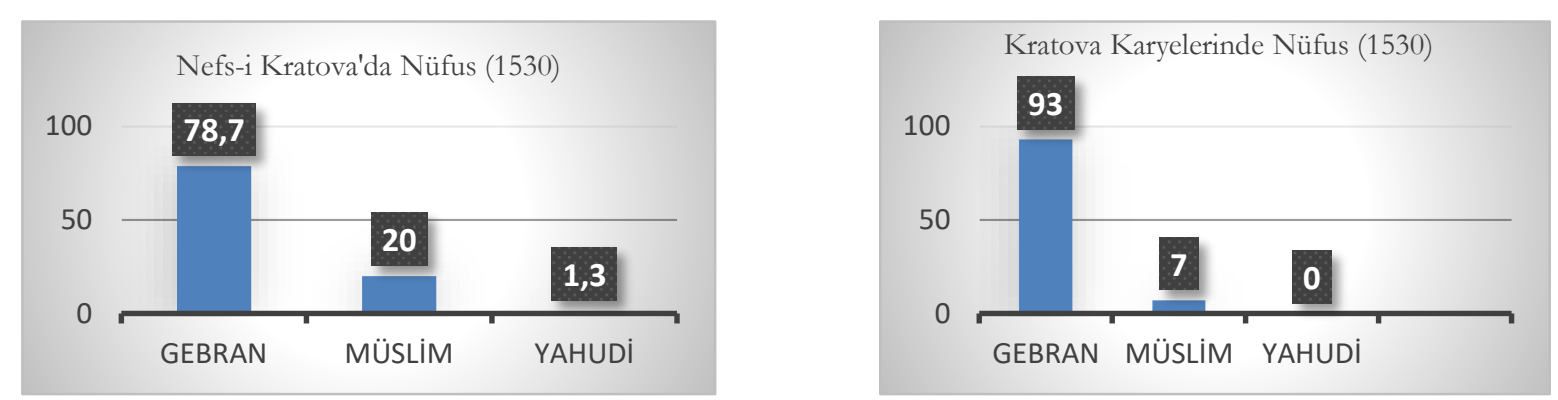

Grafik 2. 1530'da Kratova Genelinde Demografik Dağılım

Kaynak: BOA, 2003, s. 38; BOA TT nr.167, s. 245-248.

Kratova Kazasının 1530'a ait demografik yapı ve genel nüfus verilerinin akabinde kırsalda kaydedilmiş karyelerin isimleri de aşağıdaki tablo eşliğinde gösterilmeye çalışılmıştır. 
Tablo 6. 1530'da Kaza-i Kratova'da Karyeler

\begin{tabular}{llll}
\hline & & Karye İsimleri & \\
\hline 1.Petrova Kukiçe & 13.Lesnova & 25.Kurkova & 37.Lukova \\
2.Zelezniçe & 14.Muşkova & 26.Burilofça & 38.Çerminye \\
3.Tularava & 15.İstagotin & 27.Zerinçe & 39.Yalurşiçe \\
4.Talaşmançi & 16.Vurbiçe & 28.Tervasali & 40.Dolna Kursiçe \\
5.Jivaleva & 17.Nezilova & 29.Leferniçe & 41.Samova \\
6.Prikofça & 18.Kinajeva & 30.Kurserinçe & 42.Karişova \\
7.Novasil & 19.Koykova Kula & 31.Kurlakova & 43.Kurdova Kukiçe \\
8.Toydançe & 20.Dobra Luka & 32.İrlakova & 44.Toyolinçe \\
9.Sakuliçe & 21.Sas & 33.Palar nam-1 diğer Grad & 45.Yerasil \\
10.İşagova & 22.Leskova Luka & 34.Derunye & 46.Gorlançe \\
11.Filibofça & 23.İstavkoviçe & 35.İ̧̦tinye & \\
12.Gorna Kratova & 24.Bersakova & 36.Yakoştinye & \\
Kaynak: BOA TT nr.167, s. 246-248 & &
\end{tabular}

16. yüzyılın ortasına gelindiğinde Kratova kazasının demografik yapısı ve nüfusu ile alakalı veriler, 1550 tarih ve 267 numaralı tahrir defteri kayıtlarında yer almıştır. Bu defterde de Köstendil Livasına bağlı bir nahiye şeklinde kaydedilmiş olan Kratova yine padişah hassı tanımıyla yer almıştır. Ayrıca Kratova kazasının Kratova, İștip, Koçana ve Nögeriç isimli nahiyelerden müteşekkil olup ayrı bir nefsinin de kaydedildiği anlaşılmıştır. Ancak bu değişim idari taksimatta değil mukataa gelirlerinin bağlanması noktasında olup Kratova nüfusuna popülasyon olarak dahil edilmesi gerekmemektedir. Burada aslolan Kratova gibi mukataa değeri yüksek bir merkezin çevresindeki diğer merkezlerin odağına yerleştirilmesi ve Balkanlar için oldukça mühim olan bu gelir kaynaklarının takibinin düzenli olarak yapılması zaruretidir.

Kratova Kazasının kendi ismini taşıyan merkeziyle ilgili veriler, mahalleler bazında ayr1 ayrı kaydedilmiştir. Tüm bu kayıtlar ışığında Kratova Nahiyesinin demografik yapısı 1550 tarihi itibariyle merkezindeki 33 mahalle etrafinda teşekkül etmiştir. Ayrıca bu mahallelerin 5'inde Müslümanlar, 28'inde Gayrimüslimler, 1'inde Yahudiler ve 1'inde diğer defterlerden farklı olarak ilk kez karşımıza çıan Kıptilerin de kaydedilmiş olduğu anlaşılmıştır. Bahsi geçen mahallelerdeki nüfus dağılımı ise 194 Müslim hane, 3 Müslim mücerred, 402 Gebran hane, 101 Gebran Mücerred, 55 Gebran Bive, 11 Kibtiyan hane, 28 Yahudiyan hane ile avarızdan muaf 2 hane olmak üzere kayıtlara geçirilmiștir (BOA TT nr.267, s. 464472). Buradan hareketle Kratova'nın otuz yıllık bir zaman dilimi içerisinde kaza merkezindeki nüfusunda Müslim ve Yahudi ahali ile birlikte ayrıca kaydedilmiş Kıbtilerin de içerisinde yer aldığı genel bir nüfus artışı yaşanmıştır. Böylelikle hem merkezdeki mahallelerde hem de hane sayılarında tüm ahali bazında genel nüfus artışı görülmüştür. Ancak bu artış hızı Müslim ahalinin özelinde neredeyse iki katına çıkmıştır. $\mathrm{Bu}$ durum XVI. asır boyunca Osmanlı egemenliğindeki tüm topraklar üzerinde ve Balkanlar genelindeki Müslüman iskân alanlarının gelişmesi ve genişlemesiyle Anadolu'dan bölgeye getirilip yerleştirilmeye çalş̧llan Müslüman topluluğuyla açıklanabilir. Kaza merkezine Yahudiler haricinde kaydedilmiş Gayrimüslim ahalinin nüfusundaysa 1519'dan buyana süregelen düşüşün devam ettiği anlaşılmıştır.

Bu verilerden hareketle 1550 tarihinde Kratova merkezinin nüfusunun yaklaşık 3344 kişiden oluştuğu tahmin edilebilir. Ayrıca nahiye merkezindeki bu nüfusa ilaveten 4 imam, 3 müezzin, 1 hatib, eğitim zümresinden 2 muallim, bölgedeki iktisadi ve demografik kayıtları tutup gerekli yazışmaları yapmakla görevli 5 emin ile 5 katib ve kadı yerine bölgedeki hukuki işlerden sorumlu 1 naib gibi bazı dini görevlilerin de ayrıca kaydedildiği görülmüsstür (BOA TT nr.267, s. 472). Bahsi geçen görevlilerin evli olup olmadıkları hakkında defterde herhangi bir kayıt yer almamakla birlikte her bir görevlinin hanelerinin olduğu varsayllip kaza merkezi nüfusuna eklenmiş̧ir. Nihayetinde Kratova Nahiyesindeki merkez yerleşim alanının tahmini nüfusunun yaklaşık 3449 kişiden meydana geldiği ileri sürülebilir.

Defterde Kratova'nın merkezi dışında kırsalındaki 23 karyenin de ayrıca kaydedildiği anlaşılmıştır. Böylelikle Kratova kırsalındaki karyeler özelindeki demografik yapının 25 Müslim hane, 8 Müslim Bennak, 2 Nim Çift, 979 Gebran hane, 181 Gebran Mücerred, 62 Bive'nin etrafinda şekillendiği anlaşılmıştır. Ayrıca defterde Kinajeva karyesi demografik verilerinin bulunduğu verilerin ilişiğine Kusariç isimli bir mahallenin de kaydedildiği fark edilmiştir. Bu vesileyle Kratova kırsalı nüfusu hesaplanırken bu mahallenin demografik verileri nüfus toplamına eklenmiştir (BOA TT nr.267, s. 473-490). Bu vesileyle 1550 tarihi itibariyle Kratova kırsalında kayıtlı karyelerin nüfusunun da yaklaşık 5273 kişiden müteşekkil olduğu söylenebilir. Sonuç olarak aynı tarih itibariyle Kratova'nın genel toplam nüfusu yaklaşık 8722 kişi olarak tespit edilmiştir. 1550 'deki bu demografik durumun tahlilini kolaylaştırması maksadıyla Kratova'daki 
URAL

XVI. Asrın Ilk Yarısında Kratova'da Nüfus Ve Demografik Yapı

demografik yapı ile nüfus dağılımları ve kaza merkezindeki mahalle isimleri aşağıdaki tablolar eşliğinde gösterilmeye çalışılmıştır.

Tablo 7. 1550'de Nabiye-i Kratova'da Nüfus

\begin{tabular}{cccccccc}
\hline \multicolumn{7}{c}{ Nefs-i Kratova Mahallelerinde Nüfus } \\
\hline Müslim & Müslim & Görevli & Gebran & Gebran & Bive & Yahudi & Kibtiyan \\
Hane & Mücerred/Bennak/Nim & Hane & Hane & Mücerred & & Hane/Muaf & Hane \\
194 & $3 /--$ & 21 & 402 & 101 & 55 & $28 / 2$ & 11 \\
& & Nefs-i Kratova'da Nüfus: 3449 kişi & & \\
\hline \multicolumn{7}{c}{ Kratova Karyelerinde (Kırsalda) Nüfus } \\
\hline \multicolumn{7}{c}{ Nefs dişında Kratova'da Nüfus: 5273 kişi } \\
\hline \multicolumn{7}{c}{ Cem'an Nahiye-i Kratova'da Nüfus: 8722 kişi } \\
\hline
\end{tabular}

Kaynak: BOA TT nr.267, s. 464-490
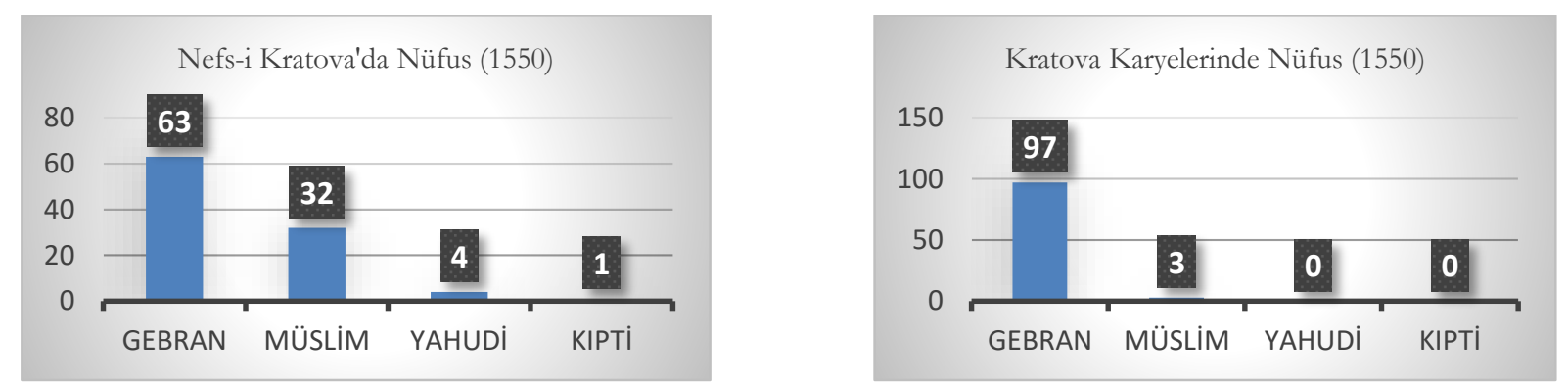

Grafik 3. 1550'da Kratova Genelinde Demografik Dağılım

Kaynak: BOA TT nr.267, s. 464-490

Tablo 8. 1550'de Nabiye-i Kratova Merkezindeki Mahalleler

\begin{tabular}{|c|c|c|}
\hline \multicolumn{3}{|c|}{ Mahalle-i Gebran } \\
\hline 1.Gorna Pop İnbomenik & 11.Mesajeçer & 21.Pop Yondar \\
\hline 2.İnbomenik & 12.Mala & 22.Zerkerilin \\
\hline 3.Pop Todor & 13.Pop İştanşe & 23.Pop Denak \\
\hline 4.Pop Dimitri & 14.Kalugun & 24.Pop Gorko \\
\hline 5.İştefan & 15.Dobra Koge & 25.Pop Nikola \\
\hline 6.Radliç & 16.Broto Pop & 26.Dugoçovik \\
\hline 7.Pavli & 17.Pop İştefan & Mahalle-i Yahudiyan \\
\hline 8.Pop Mihal & 18.Doykin & 1.Cemaat-i Yahudiyan \\
\hline 9Pop Reka & 19.Pop Petko & Mahalle-i K1btiyan \\
\hline 10.Pop Yovan İștefan & 20.Pop İstoyko & 1.Cemaat-i Kibtiyan \\
\hline \multicolumn{3}{|c|}{ Mahalle-1 Müslim } \\
\hline 1.Cami-i Şerif & 3.Mescid-i Hac1 Kemal & 5.Darbhane/Hacı Karagöz \\
\hline 2.Mescid-i Ferman Hatun & 4.Mescid-i Hasan Çelebi & \\
\hline
\end{tabular}

16. asrın ilk yarısında Kratova'daki demografik dağılım verileri, kaza merkezi ve kırsalındaki yerleşimin mahalle ve karye dağılımları yukarıda yer alan tablolar, grafikler ve izahatları eşliğinde bahsedildiği üzere gerçekleşmiştir. Bu vesileyle Kratova'daki genel demografik yapıyı aynı anda görüp anlamlandırabilmek maksadıyla tüm veriler aşağıdaki tablo eşliğinde de aktarılmaya çalışılmıştır. 
Tablo 9. XVI. Asrn Illk Yarısnda Kratova'da Toplam Nüfus

\begin{tabular}{|c|c|c|c|c|c|c|}
\hline \multirow[t]{2}{*}{ Tarihler } & \multicolumn{2}{|c|}{1519} & \multicolumn{2}{|c|}{1530} & \multicolumn{2}{|c|}{1550} \\
\hline & Nefs & Karye & Nefs & Karye & Nefs & Karye \\
\hline Müslim Hane & 155 & 18 & 165 & 174 & 195 & 25 \\
\hline Müslim Mücerred & & & & & 3 & \\
\hline Müslim Bennak & & & & & 8 & \\
\hline Müslim Nim & & & & & 2 & \\
\hline Gebran Hane & 982 & 1189 & 606 & 2101 & 402 & 979 \\
\hline Gebran Mücerred & & 26 & & 204 & 101 & 181 \\
\hline Gebran Bive & 65 & 34 & 73 & 162 & 55 & 162 \\
\hline Yahudi Hane & 10 & & 11 & & 28 & \\
\hline Kıpti Hane & & & & & 11 & \\
\hline Toplam & & & & & & \\
\hline
\end{tabular}

Kaynak: BOA, 2003, s.11-46; BOA TT nr.74, s. 1-5; MAD nr.170, s. 3-16; BOA TT nr.167, s. 245-248; BOA TT nr.267, s. 464490.

Nihayetinde 16. asırda nefs-i Kratova mahallelerinde inanç gruplarına göre nüfus verileri ile kırsalda kayıtlı karye sayıları da aşağıdaki tablolar eşliğinde aktarılmaya çalışılmıştır.

Tablo 10. XVI. Asrm İlk Yarsinda İnanc Gruplarna Göre Nefs-i Kratova'da Mahalleler

\begin{tabular}{lccc}
\hline \multicolumn{1}{c}{ Mahalleler } & Tarih & Tarih & Tarih \\
\hline & 1519 & 1530 & 1550 \\
Gebran Mahalle & 15 & 24 & 26 \\
\cline { 4 - 6 } Müslim Mahalle & 1 & 3 & 5 \\
\hline Yahudi Mahalle & 1 & 1 & 1 \\
\hline Kupti Mahalle & - & - & 1 \\
\hline \multicolumn{1}{c}{ Toplam } & $\mathbf{1 7}$ & $\mathbf{2 8}$ & $\mathbf{3 3}$ \\
\hline
\end{tabular}

Kaynak: BOA, 2003, s. 11-46; BOA TT nr.74, s. 1-5; MAD nr.170, s. 3-16; BOA TT nr.167, s. 245-248; BOA TT nr.267, s. 464490

Tablo 11. XVI. Asrn Ille Yarnsinda Kratova'da Karye Saynlar

\begin{tabular}{lccc}
\hline & Tarih & Tarih & Tarih \\
\hline & 1519 & 1530 & 1550 \\
Karye Sayıs1 & 21 & 46 & 23 \\
\hline
\end{tabular}

Kaynak: BOA, 2003, s. 11-46; BOA TT nr.74, s. 1-5; MAD nr.170, s. 3-16; BOA TT nr.167, s. 245-248; BOA TT nr.267, s. 464490

\section{Sonuç}

Kratova'nın XVI. yüzyılın ilk yarısı itibariyle ve farklı arşiv kayıtları doğrultusunda demografik yapısı ve nüfus verileri dikkate alındığında gayrimüslim nüfusun Gebran ve Yahudiyan ifadeleriyle kaydedildiği anlaş1ırken, Müslümanların ise Müslim ifadesiyle kaydedildiği görülmüştür. Bu haliyle bahsi geçen asrın ilk yarısında Kratova'daki demografik dağılım bu inanç gruplarının etrafinda şekillenmiştir diyebiliriz. Ayrıca kaza genelindeki demografik yapıya 1550 itibariyle Kıbtiyan ifadesiyle Kıptiler de kaydedilmiştir. Çalışma genelinde Kratova'nın nefsi ve karyelerindeki nüfus ayrı ayrı ele alındığından bu noktada çıkarımlarımızı da ayrı ayrı yapmaya çalışacağız. Böylelikle kaza merkezindeki demografik yapı ve nüfus verileri ile karyeler etrafında şekillenen demografik yapı ve nüfus verilerini ayr1 ele alıp değerlendireceğiz.

16. astın ilk yarısında kaza genelindeki nüfus verileri dikkate alındığında Kratova'da gayrimüslim ahalinin nüfusunun düşüş veyahut artış hızının nefs ile kırsal alan etrafinda farklı bir ivme gösterdiği anlaşılmıştır. Öyle ki kaza merkezinde kayıtlı gayrimüslim nüfusun kırk yıllık süre içerisinde gözle görülür bir düşüş gösterdiği fark edilmiştir. Nihayetinde Kratova nefsindeki veriler eşliğinde nüfustaki bu düşüşün 1519'dan 1550’ye gelindiğinde \%50'lere kadar ulaştığ1 görülmüştür. Aynı tarihlerde Kratova merkezindeki Müslüman nüfustaysa sınırlı da olsa bir artış söz konusu olmuştur. Bu durum kendisini 1519'dan 1550'ye gelindiğinde \%15'lik bir artış oranıyla göstermiştir. Ayrıca kaza merkezindeki demografik dağılım içinde gayrimüslim ahaliden ayrıca kaydedilmiş olan Yahudi nüfusun bahsi geçen tarihlerde ve hane bazında oldukça az olduğu görülse de düzenli ve dikkat çekici bir artış hızı gösterdiği de anlaşılmıştır. Hatta 1519'a göre 1550 tarihinde bu artıs hızının \%300'lere kadar ulaşı̆ı̆ı da anlaşılmışır. Lakin bahsi geçen yüzyılın ilk yarısı itibariyle geçen elli yıllık süre dahilinde Kratova merkezindeki genel demografik yapı içerisinde Gayrimüslimlerin nüfusunun Müslüman nüfusa göre oranı oldukça yüksektir. Ancak kaza merkezindeki bu nüfus fark1 zamanla belirli düzeyde azalma göstermiştir. Örneğin 1519'da Gayrimüslimler kaza 
merkezindeki nüfusun \%85'ini oluştururken, 1530 'da bu oran \%74'e ve 1550 'deyse \%54'e gerilediği anlaşılmıştır. Bu veriler 1şığında ve elde edilen sonuçlar dahilinde Kratova merkezinde genel manada bir ihtida hareketinden ziyade, bölgeye Müslüman nüfusun yerleştirildiği fikrini daha fazla ön plana çıkarmaktadır. Bu durum bahsi geçen yüz yıl genelinde ziyadesiyle Balkanlara Anadolu coğrafyasından getirilip iskân edilmeye çalışılan Türk nüfusuyla açıklanabilir. Yine aynı tarihlerde Kratova'daki Yahudi ve Kıbti nüfuslarındaki artış hızı da dikkate alındığında, bölgede bir ihtida uygulamasından bahsetmek mümkün değildir. Kaldı ki Kratova'nın genel nüfusunda en yoğun olarak yer alan ahali Gayrimüslimler olup bu durum bahsi geçen asrın tamamında hâkim olmuştur.

Çalışmada daha önce XVI. asıın ilk yarısında ve farklı tarihlerdeki tahrir ve maliyeden müdevver kayıtları incelenmiş ve Kratova'daki karyelerin isimleri ile sayıları tablolar eşliğinde aktarılmıştı. Buradan hareketle Kratova kırsalındaki karyelerdeki demografik yapı ve nüfus değişimlerine bakıldığında da yıllara göre kırsaldaki karye sayılarında ve buralara kaydedilmiş nüfusta da bazı değişimlerin yaşandığı fark edilmiştir. Mesela 1519'da kayıtlı 21 karyede 6095 kişi kaydedilmiş iken, 1530'da karye sayısı 46'ya çıkmış ve bu karyelere de 11.796 kişinin kaydedildiği anlaşılmıştır. Yine tarihler 1550'ye geldiğinde ise karye sayısında bir gerileme söz konusu olmuş ve 23 karyede 5313 kişi kayıt altına alınmıştır. Bu noktada 1519'da Kratova'ya bağlı halde kaydedilmiş 23 karyenin 1550'de İştib Nahiyesi nüfusuna dahil edildiği fark edilmiştir (BOA, T'T nr267: 492-510). Bu durum Kratova'nın Osmanlı idari mekanizması içerisindeki değişimlerin Kratova'nın demografisi ve nüfusuna yaptığı etkilerle açıklanabilir. Bu doğrultuda Kratova kırsalındaki demografik yap1, Yahudi ve Kıpti nüfusunun bulunmaması noktasında kaza merkezinden ayrılmıştır. 16. Yüzyılın ilk yarısında Kratova kırsalında gayrimüslim ahali arasında hiç Yahudi ve Kıpti nüfus kaydına rastlanılmamıştır. Kratova kırsalındaki karyeler özelindeki demografik yapı ve nüfusun değişim süreçleriyse 1519'dan 1550'ye kadarki zamanda büyük bir farkla gayrimüslim nüfusun sayısal çoğunluğunda nüksetmiştir. Mesela 1519'dan 1550'ye gelindiğinde gayrimüslimlerin Kratova kırsalındaki nüfus yoğunluğu \%99’a kadar ulaşmışır. Bu haliyle kaza merkezindeki kayıtlı Müslüman nüfusun kırsalda pek yaşamadığ1 ortaya çıkmıştır.

Kratova'nın merkezindeki nüfus ve demografik yapıda Müslüman ahalinin mevcut durumu tüm veriler değerlendirildiğinde merkez mahalleleri etrafında dağılım göstermiştir. Bu durum Balkanların genelinde görülen ve Müslim ahalinin genellikle şehir ve kaza merkezlerindeki mahallelerde iskân edilmesiyle doğru orantılı olarak açılanabilir. Hatta kaza merkezinde kurulan yeni mahalleler bahsi geçen Müslimler için oluşturularak bu haliyle kaydedilmiştir. Ayrıca aynı tarihlerde Nefs-i Kratova'da kayıtlı mahalle sayıları ile isimlerinde de bazı değişikliklerin yaşandığ tespit edilmiştir. Örneğin 1519 'da Kratova merkezindeki mahalle sayısı 17 iken, 1530 'da 28'e ve 1550'de de 33'e yükselmiştir. Mahalle sayılarındaki bu artış kendisini her inanç grubunda da göstermiştir. Mesela 1519'daki mahallelerin 15'inde gayrimüslimler, 1 'inde Müslümanlar ve 1 'inde de Yahudiler kayıtlı iken, 1530'da gayrimüslimlerin 24, Müslümanların 3 ve Yahudilerin de 1 mahallede kaydedildikleri görülmüştür. 1550'de ise 26 mahallede gayrimüslimler, 5 mahallede Müslümanlar, 1 mahallede Yahudiler ve 1 mahallede de Kiptiler kaydedilmiştir. Bu durum kaza genelindeki genel nüfus artışılla doğru orantılı olarak gelişen bir sürecin sonucu olarak açıklanabilir. Yine bu mahallelerin isimleri dikkate alındığında da gayrimüslimlerin yaşadığı mahallelerin isimlerinin başında Balkanlarda genellikle "papaz" manasına gelen "pop" ifadesinin kullanıldığı görülmüştür. Müslümanların kayıtlı olduğu mahallelerin adlarının ise daha çok cami ve mescit isimleri ile bazı kişi isimleri ve merkezde yer alan darphaneden mütevellit onun ismi ön plana çıkmıştır. Yahudilerin yer aldığı mahalle "cemaat-i Yahudiyan" ifadesiyle kaydedilirken, Kıptiler de "cemaat-i Kıbtiyan" şeklinde kaydedilmiştir (BOA MAD nr.170, s. 4-9; BOA TT nr.167, s. 145; BOA TT nr.267, s. 464-472).

En nihayetinde bahsi geçen asırda Kratova'nın da içerisinde bulunduğu Balkan coğrafyasında demografik yap1 Gayrimüslimler, Müslimler, Kıbtiler ve Yahudiler üzerinde süregelmiştir. Bu demografik dağıllım kendisini nüfus istatistiklerinde de ayrı ayrı artış veyahut düşüş ivmeleri şeklinde göstermiştir. Müslim ahalinin nüfusu Balkanlardaki hemen hemen her yerleşim bölgesinde ve belirli bir hızda artş̧ eğiliminde olmuştur. Bu artış hızı Yahudi ahali için de benzerlik göstermiştir. Bu durumun sebebi Müslim ahalinin Anadolu'dan ve Yahudi ahalinin de başta Selanik olmak üzere Balkanların diğer bölgelerinden Kratova'ya getirilip iskân edilmesiyle açıklanırken hem araştırmamıza konu olan Kratova özelinde hem de diğer civar Balkan şehirlerinde de benzerlik göstermiştir. Yeni arazilerin işlenmesi ve ek vergi gelirinin elde edilmesi gibi bu unsurlar Osmanlı idaresinin Balkan coğrafyasını belirli oranlarda insan kitleleriyle iskâna tabi tutmasıyla açıklanabilir. Burada dikkat edilmesi gereken husus ise Kratova özelinde gayrimüslim ahalinin nüfusundaki yoğunluğun XVI. asrın ilk yarısında belirgin bir biçimde Müslümanlar ve Yahudilerden fazla olması ve buradan hareketle baskın bir ihtida hadisesinin yaşanmamış olmasıdır. Bu 
durum kendisini hem gayrimüslim ahalinin nüfus verilerinde hem de Yahudi nüfusunun giderek artış göstermesi üzerinde gösterebilmiştir. Böylelikle gerek Balkanlar genelinde gerekse Kratova özelinde Osmanlı hakimiyetinin yoğun olarak kurulmaya çalışıldığı XVI. asırda demografik dağılım ve nüfus dengeleri üzerinde büyük bir değişiklik oluşturmadan ve Osmanlı siyasal egemenliğinin doğal bir sonucu olarak Müslim ahali eksenindeki artışla sürdürmüştür.

\section{Etik Beyan}

"XVI. Asrnn Illk Yarssı Karatova'da Nüfus Ve Demografik Yapı” isimli çalışmanın yazım sürecinde bilimsel etik ve alıntı kurallarına uyulmuş; toplanan veriler üzerinde herhangi bir tahrifat yapılmamış ve bu çalışma herhangi başka akademik yayın ortamına değerlendirme için gönderilmemiştir. Bu araştırma doküman incelemesine dayalı olarak yapıldığından etik kurul kararı zorunluluğu bulunmamaktadır.

\section{Kaynakça}

167 Numaral Mubasebe-i Vilayet-i Rum İli Defteri (937/1530) (2003). Ankara: Başbakanlık Devlet Arşivleri Genel Müdürlüğü Osmanlı Arşivi Daire Başkanlığı Yayınları.

Barkan, Ö. L. (1953). Tarihi Demografi Araştırmaları ve Osmanlı Tarihi. Türkizat Mecmuası X, 1-26.

Baştav, Ş. (1989). Bizans Imparatorluğu Taribi Son Devir. Ankara: TKAE Yayınları.

Beldicianu, E (1995). Osmanlı İmparatorluğunun Örgütü. İçinde R. Mantran (Edt.). Osmanh İmparatorluğu Taribi. (ss.145-170). İstanbul: Cem Yayınevi.

Çiçek, K. (1995). Osmanlı Tahrir Defterlerinin Kullanımında Görülen Bazı Problemler ve Metod Arayışları. Türk Dünyası Arasttrmalarn Dergisi 97, 93-111.

Emecen, F. (2014). Defteri Köhne Pirlepe Kırçova Kesiminin En Eski Tımar Defteri. Osmanl Arașturmalar Dergisi 43 (43), 341-474.

Göyünç, N. (1979). Hane Deyimi Hakkında. İstanbul Üniversittesi Edebiyat Fakültesi Tarib Dergisi XXXII, 305-335.

Gümüşşü O. (2001). XVI. Yü̈yylda Larende Karaman Kaz̧asinda Yerleşim ve Nüfus. Ankara: TTK Yayınları.

İnalcık, İ. (1992). Bayezid I. Diyanet İslam Ansiklopedisi 5, İstanbul: Diyanet Vakfi, 231-234.

İnbaş1, M. (2012). Üsküp, Diyanet İslam Ansiklopedisi 42, İstanbul: Diyanet Vakfi, 377-381.

Kahraman, A. ve Dağlı A. (2010). Evliya Celebi Seyahatnamesi. İstanbul: Yapı Kredi Yayıncilık.

Kiel, M. (2009). Selanik, Diyanet İslam Ansiklopedisi, 36, İstanbul: Diyanet Vakfi, 352-357.

Kratova Belediyesi Resmi Web Sitesi (2021). Belediye Bilgilendirme Sitesi. Erişim adresi: http://www. http://www.opstinakratovo.gov.mk/wp-content/uploads/2015/11/Opstina_Krotovo-Profil.pdf

Osmanl Yer Adlar I (2013). Ankara: Başbakanlık Devlet Arşivleri Genel Müdürlüğü Osmanlı Arşivi Daire Başkanlığı Yayınları.

Republic of Macedonia Municipality Kratovo (2015). Project Appraisal Document. Constrruction of new green market in the municipality Krotovo. Erişim adresi: https:// finance.gov.mk/wp-content/uploads/2009/09/PAD_Kratovo-za-naweb.pdf.

Telli, H. (2020). Osmanlı Döneminde Makedonya Kratova’da Eğitim Kurumları. A. İmamoğlu (Edt.). İçinde Balkanlar ve İslam Kongresi (ss.307-324). Edirne, Edirne: Trakya Üniversitesi Yayını.

Türkiye Cumhuriyeti Devleti Cumhurbaşkanlı̆̆ Devlet Arşivleri Başkanluğı. Başkanlık Osmanlı Arşivi (BOA). Tapu Tahrir Defterleri Tasnifi, TTd.nr.74

Türkiye Cumhuriyeti Devleti Cumhurbaşkanlığı Devlet Arşivleri Başkanlığı. Başkanlık Osmanlı Arşivi (BOA). Maliyeden Müdevver Defterleri Tasnifi, MAD.nr.170

Türkiye Cumhuriyeti Devleti Cumhurbaşkanlığı Devlet Arşivleri Başkanlığı. Başkanlık Osmanlı Arşivi (BOA). Tapu Tahrir Defterleri Tasnifi, TT.nr.167

Türkiye Cumhuriyeti Devleti Cumhurbaşkanlığı Devlet Arşivleri Başkanlığı. Başkanlık Osmanlı Arşivi (BOA). Tapu Tahrir Defterleri Tasnifi, TT.nr.267

Yavuz, E. (1989). Osmanl Imparatorluğunda Bulgarlar Voynuklar. Ankara: TTK Yayınları.

\section{EXTENTED ABSTRACT}

After completing its establishment in Western Anatolia, the Ottoman Empire planned its expansion policies towards the west. As a result of the conquests made by the Ottomans towards the west, they gained sovereignty in the Balkan geography. First of all, the target was the conquest of Gallipoli. The main goal was to reach the Balkans after Gallipoli. For the Ottomans, dominating the Balkans is the key to entering Europe. The permanence of the Ottomans in the Balkans was achieved thanks to the conquest and settlement policy they applied in the region. The Ottomans first understood the geography of the Balkans and then tried to get to know their people. Afterwards, they determined the census of both Balkan lands and society. This census was recorded in Ottoman archive documents under the name tahrir. Tahrir operation was carried out generally every thirty years within every century. It is known that counts are made outside of this situation and for different reasons. Important demographic and numerical 
population data of the Balkans are recorded in these archive documents. The lands suitable for agriculture in the Balkans were determined as a result of this census. In addition, the population and demographic structure have been revealed along with the lands in the region. As a result of this information, the Ottomans also planned the income they could obtain from the Balkans.

As a result of this practice, they were able to apply an Ottoman style administrative style in the fertile Balkan geography. Another result of the Ottoman population and land census system was that it facilitated the determination of other settlements in the Balkans. The Ottomans evaluated the results of these census procedures very well. In this way, a new demographic structuring was aimed, according to the population density in the Balkans. The regions in which the population to be brought from Anatolia will be settled in the Balkans is also planned accordingly. In this way, both the Balkans were Turkified and the state was able to obtain a large amount of tax income over this region.

Ottoman history researchers have made many examinations on these census statistics. These researches revealed the demographic distribution and population density in the Balkan geography under the Ottoman rule. As a result of these studies, the population and settlement activities of the Ottomans in the Balkans were tried to be enlightened. Kratova, which is an important settlement area in the Balkans due to its underground wealth and geographical conditions, was at the center of our study. The city of Kratova was established at the foot of the Osogova Volcano, one of the volcanoes in the Balkans that has recently lost its effectiveness. Thanks to the Zletovo and Kriva Rivers fed by the Vardar River, Kratova and its vicinity have come to the fore in terms of both agricultural activities and mining. Today, Kratova is located within the borders of the North Macedonia State. It is administered as a municipal administrative unit within the political structure of the state. Despite the cold and harsh climate of the Balkans, Krataova has a mild climate both in winter and summer due to rainfall. It is known for its richness in copper, silver, lead, gold and zinc. It maintained this feature throughout the Ottoman State administration. For this reason, it had a special importance in the administrative and economic structure of the Ottoman Empire. In addition to this situation, many grain products can be grown in agricultural lands due to the favorable climate.

The history of Kratova is VI. It dates back to the century. Kratova remained under the rule of the Roman Empire until the 5th century after Christ. Until the Xth century, it was ruled under the political rule of Byzantium. Kratova, which was ruled by the Serbian Kingdom between 980-1015, XIII. Century again came under the control of Byzantium. The Ottoman rule in Kratova, on the other hand, was XIV. It started in the second half of the century. Considering this historical past, Kratova was an important settlement area during the political rule of both Slavs and Turks in the Balkans. Kratova also had a strategic importance for the Ottoman Empire. Kratova was located on the route that the Ottomans called as the left arm in their raids towards the interior of Europe. In addition, due to its proximity to Köstendil, it was located on a passageway dominated by the Danube region. For this reason, Kratova and its vicinity became an important settlement area for the Ottomans. As a result of the Ottoman raids, XIV. At the end of the century, Kratova was conquered. After the conquest of Kratova, the northeastern Macedonia region became a base point for the planned raids to both Bulgaria and Albania.

Kratova, XVI. Century, it was included in the administrative structure of the Ottoman Empire as an accident center registered in Köstendil Liva. XVI. century and in the Ottoman records prepared in 1519, 1530 and 1550, Kratova was recorded in the land of the sultan. In 1519, the districts of Menlik, Shtip, Strumica, Ilica, Bedriç, Ivranya, Radomir, Dupnice, Tikveş, Praşova and Şirişnik, including Kratova, formed the province of Köstendil.

In the Ottoman records, the population of Kratova in 1519 was recorded in two different styles. XVI. In the first half of the century, under the Ottoman administration, Kratova took place as the town center and the surrounding villages. In this study, the population of the town center and the surrounding villages were considered separately. In this way XVI. In the first half of the century, Kratova's demographic situation, population and the transformation process in the mentioned century were tried to be enlightened. In the study, agricultural activities of Kratova were determined along with the demographic structure and population data. On this axis, evaluations were made about the economic structure of Kratova. As a result of the study, XVI in Kratova, which was under the rule of the Ottomans in the Balkans. The demographic distribution, population change process, agricultural production and economic income level in the first half of the century have been revealed. Thus, the population and economic place of Kratova in the Ottoman rule in the Balkans was also revealed. 
As a result XVI. In the first half of the century, the demographic structure in Kratova was composed of non-Muslims, Muslims, Qibians and Jews. This demographic distribution has shown itself in the form of increases or decreases in population statistics separately. This rate of increase was similar for the Jewish population as well. The reason for this situation can be explained by the fact that Muslims were brought from Anatolia and Jews were brought from other parts of the Balkans, especially Thessaloniki, and settled here. This situation has shown similarities both in Kratova, which is the subject of our study, and in other surrounding Balkan cities. This approach can be explained by policies such as the Ottoman administration's efforts to bring masses of people to the region and settle them in order to cultivate the lands in the Balkans and to obtain additional tax income. The point to be considered here is XVI. In the first half of the century, the non-Muslim population in Kratova was more than the Muslims and Jews. Based on these data, it can be said that there was no dominant religious conversion in Kratova and its vicinity. This claim can be supported by the fact that both the non-Muslim population and the Jewish population in Kratova have increased to a certain extent. Thus, it can be said that the demographic distribution and population balances in and around Kratova did not change significantly during the period when the Ottoman rule in the Balkans increased in the 16th century. 